\title{
Potentialities and constraints in the relation between social innovation and public policies: some lessons from South America
}

\author{
Ariel Gordon $^{1}$, Lucas D. Becerra $^{2}$ and Mariano Fressoli ${ }^{3}$
}

\begin{abstract}
Social innovation (SI) can offer alternative forms of organization and novel solutions to complex problems faced by contemporary societies. As governments face increasing pressures from mounting societal challenges, it is assumed that SI can provide bottom-up solutions in ways that can create transformative change. However, the dialectic relation between bottom-up initiatives and government can be difficult and sometimes contradictory. Even more, assumptions about the diminishing powers of government can be misleading and overstress the role of SI. Based on the study of the recent South American experience, we have departed from this assumption, seeking to understand what the role of public policies as initiators or supporters of SI could be. We analyzed two top-down initiatives promoted by public policies that ultimately fostered SI in Argentina, the subsistence agriculture "Pro-Huerta" program and the policies of the National Technology and Social Innovation Program, and one complementary case study of a bottom-up SI experience in Brazil, the One Million Cisterns Program, which was later inserted into public policies. Together, these cases have allowed us to understand the potentialities and limitations of SI and the kind of dialectic relations they established with public policies. In particular, we have considered how public policies can foster and support SI.
\end{abstract}

Key Words: public policy; social innovation; South America; state

\section{INTRODUCTION}

Historically, innovation has been associated with changes in technology, i.e., increases in productivity and new products, and the social organization of production, i.e., changes in wage/capital ratio, profit bias in knowledge generation, and so forth, which have an impact on the capabilities of individual firms and the economy as a whole. However, the concept of innovation has expanded in the last 20 years to refer to new ways of improving capabilities for meeting social needs. ${ }^{[1]}$

The concept of social innovation (SI) expresses these changes. There is a recent and growing wealth of literature on SI, addressing the different dimensions of the concept, both theoretically and empirically (Mulgan 2006). Moreover, the concept of SI has received attention from governments, international organizations, and nongovernmental organizations (NGOs) informing official policy visions. Thus, the question of the governance and institutionalization of SI is an emerging field in the study of SI phenomena (Franz et al. 2012, Seyfang and Haxeltine 2012, Smith and Raven 2012, Avelino et al. 2014, Pel and Bauler 2014).

In this sense, we aim at advancing the understanding of the link between public policies and SI, particularly as regards the potential role of public policies when launching and fostering or constraining SI initiatives to transform social change. This leads to the question of transformative change in terms of institutional change, understood as "change that challenges, alters and/or replaces established (and/or dominant) institutions in (parts of) the social-material context" (Haxeltine et al. 2016:19). To advance the understanding of the relation between SI and public policies, we follow the definition of transformative social innovation (TSI) proposed by Haxeltine et al. (2016:19) as a "process, through which social innovations challenge, alter and/or replace established (and/or dominant) institutions in the social-material context."
There is a need for a greater understanding of the relationships between SI and public policy. We critically discuss certain established conceptions and public discourse on SI regarding the role of government. Then, the analysis is focused on three empirical case studies from Argentina and Brazil involving public policies and SI. We seek to explore the relationships between SI and public policies as these are demonstrated through the case studies, each of which offers insights into these relationships and the tensions involved. A basic classification of the roles of public policies regarding SI for social change is put forward. Finally, we discuss empirical case studies and present the conclusions, advancing preliminary answers to the research questions, in the context of the discussion of transformative SI.

\section{METHODOLOGY AND THEORETICAL RATIONALE}

To analyze the public policy design oriented toward fostering SI, we employ the approach of Rip and van der Meulen (1996) used in the analysis of research and innovation public policies. As stated by these authors, research systems imply a balance between steering, i.e., the extent to which the system is sensitive to attempts of a principal, generally the government, to implement own objectives, and aggregation, i.e., the organization of processes of bottom-up agenda building within the system.

This is because of the intrinsic asymmetries of information and knowledge between principal, i.e., the government, and agent, i.e., the research community, in scientific and technological research. We argue that, regarding SI, as a social process of innovative and transformative practices, there is a similar asymmetry of knowledge and information between principal and agent, thus requiring an interaction between top-down and bottom-up initiatives. This is not only a normative position regarding the importance of public participation in SI in terms of legitimacy, but also an analytic view on the dialectic relation between public policies and SI. This leads to understanding TSI as a process that alters existing patterns of structuration resulting in varying degrees of institutionalization in

\footnotetext{
${ }^{1}$ Departamento de Economía y Administración (DEyA), Universidad Nacional de Quilmes (UNQ), ${ }^{2}$ Instituto de Estudios sobre la Ciencia y la Tecnología (IESCT), Universidad Nacional de Quilmes (UNQ), Consejo Nacional de Investigaciones Científicas y Técnicas (Conicet), ${ }^{3}$ Centro de Investigaciones para la Transformación (Cenit), Consejo Nacional de Investigaciones Científicas y Técnicas (Conicet)
} 
a dialectic relationship with the context (Haxeltine et al. 2016:21-22). The relation between SI and public policies has to deal with this dialectic and bidirectional nature.

However, this bidirectional relation can take different forms. Starting from the selection of public policies that foster SI in South America, the analyses of different kinds of relations between government and SI experiences allowed us to generate a basic typology.

In this sense, four main rationales explain the selection of case studies:

1. There are public policies that start and foster SI processes.

2. The public action was oriented to solve social problems related to poverty stimulating SI.

3. The cases show three types of relations between public policy and SI: linkage fostering (Pro-Huerta program), direct intervention (National Technology and Social Innovation Program [PNTIS]), and a mixed position (One Million Cisterns Program [P1MC]).

4. The cases show bottom-up and top-down styles of policy design.

The linkage-fostering type involves building up agendas, fostering the establishment of a certain field, and creating incentives for the promotion of cooperation. The other possible role implies the direct intervention in the process of social organization and provision of public goods in innovative ways that foster social change. In addition, differences between bottom-up and topdown initiatives can be established. As we mentioned, the relation between public action and social change has to be rethought, but, at the very beginning, when the action is being planned, we can characterize it as a bottom-up or top-down action.

Finally, there is a last, but not least, reason for our analysis. In South America, and especially in Argentina and Brazil, there is abundant evidence that a main local game changer, i.e., the severe economic and social crises experienced in the late 1990s and early 2000s, was a trigger for experimentation in SI and public policies. Therefore, these two countries offer valuable insights for the analysis of the relation between SI and public policies for other countries and regions. Particularly, we advance new evidence and insights, related to the role of the state and the civil society, to understand how SI initiatives are developed and sheltered in nonEuropean volatile economic contexts.

\section{EMPIRICAL CASE STUDIES}

\section{Perspectives on social innovation and the question of the role of government}

We now discuss the dialectic relations between SI initiatives and the role of government. Particularly, we want to critically consider the assumption in certain mainstream conceptions of SI (Bureau of European Policy Advisors [BEPA], European Commission 2011), which see it as a pseudomechanism to help government in the provision of social services.

First of all, the relation between government and SI does not run in a linear fashion. As Pel and Bauler (2014) point out, the question of SI governance and institutionalization is dialectic, complex, and somehow inherent to SI itself, as SI promotes the emergence of new ways of governance, understood as forms of social coordination. On the other hand, SI as a performative concept is currently informing official policy visions from governments at different levels through different interpretations, translations, and appropriations (Latour 2005). Therefore, SI governance emerges also as a question of statecraft and the public policy agenda itself. The institutionalization of SI, the issue of SI scaling up, involves different modes of government intervention that present risks of capture and opportunities for transformation. In this regard, SI initiatives have to navigate in a gray area between breakthrough and capture (Pel and Bauler 2014).

However, there is a crystalized academic and policy-making perspective, according to which SI has two potential outputs (Bekkers et al. 2013):

1. Resolution of major social challenges, i.e., unemployment, immigration, education and health services, use of energy, and social housing, among others.

2. Redistribution of citizen-government roles, i.e., detection of social problems, delivery of social services, provision of cultural goods, and generation of credit for consumption.

As Pel and Bauler (2014) point out, considering SI as a boundary concept helps to bring out the politics involved with its interpretation and application, thus situating SI in the middle of governance networks. The dialectic relation between SI and public policies is expressed in its unstable identity, subject to interpretation and translation from different actors. In this sense, a certain conception of SI is appropriated by mainstream political discourse promoting SI as a substitute for a welfare state under financial pressures.

This vision of SI is offered, for example, by the BEPA report:
Novel solutions must be sought. ... Solutions must be found, in a time of major budgetary constraints, to deliver better services making more effective use of available resources. In this context, social innovation represents an important option ... to innovate in a different way ... and to generate primarily social value. (BEPA, European Commission 2011:30)

As Haxeltine et al. point out: "The hypothesis implicit in the BEPA report is that social innovation builds social capital and capacities relevant for the general innovativeness of society and, by implication, gives scope for new ways to address (systemic) challenges and meet reformulated policy goals" (Haxeltine et al. 2013:4).

Our argument is that the assumption about the state being helped by SI, as posited in the BEPA report, bears problematic assumptions about both the role of the state and public policies, as well as about the potentialities and constraints of SI networks and movements to foster transformative social change.

First, it is important to address the assumptions about SI. The idea of SI as a solution for pressures faced by the state assumes that SI can help build solutions to intractable problems. Undoubtedly, SI can inspire the construction of alternative pathways for social change, but SI should not be regarded as social change itself. Also, the way in which SI can contribute is diverse. 
For instance, SI can provide alternative frames for the construction of problems and solutions, it can provide specific technologies or cognitive solutions, and, finally, it can also build models for social change (Fressoli et al. 2014).

However, the way in which SI can contribute to the solution of intractable problems will vary extensively on the differentials of power and interest between SI movements and networks, and the government or other actors. For example, new ways of credit supply to unemployed people can clash with financial, fiscal, and tax regulations. In this sense, there is a relation not only between SI and government, but private banks, international regulations, and supranational organizations are part of the "credit regime" as well.

Second, SI's contribution to the alternative pathways of social change does not necessarily provide a blueprint for public policy; this process of translation between levels, i.e., the practitioner and the policy-maker levels, is where public policies can and should play a role. The translation process may happen in several ways: from taking inspiration and ideas of bottom-up SI solutions to sheltering SI experiences to create niches of experimentation. However, most importantly, public action can foster processes of systemic social transformation. This requires the identification and empowerment of social practices, followed by scaling it up by the promotion of public policies.

Thus, reconsidering the role of government as a facilitator of social change, and seeing not only its constraints, but also its potential capabilities, can also help to recognize what resources it can mobilize to foster SI. Subsequently, we present three cases in which government acted as promoter of SI in South America.

\section{Three case studies from South America}

In the early 2000s, Argentina and Brazil faced the peak of a longstanding economic and social crisis that was the result of years of neoliberal policies. Although the two countries were affected to a different extent and dealt with the crisis in their own way, they shared similar characteristics in terms of social exclusion and reduction of government capabilities, which eventually resulted in social turmoil. In that sense, the neoliberal period of the 1990s acted as a huge laboratory for social movements and strategies of contestation and SI, which would later find a niche for development during the 2000s.

After the election of populist governments in 2003 in both countries, ${ }^{[2]}$ the role of government and public policies for SI changed extensively. Furthermore, a huge part of those initiatives was later supported and sheltered by the governments. Thus, it is possible to say that the economic and social crises in both countries triggered a wave of SI at different levels.

With the end of the crisis, the process of strengthening government capabilities, recovering the formal economy, and reinforcing government-led social policies changed the general scenario in which these initiatives were developing. Public policies played a different role, at times reinforcing SI initiatives and at times diminishing their impact, either through co-optation or competition from government-led social policies. At the same time, instead of diminishing its power, the arising of populist governments led to strengthened public policies in both countries, which were key in the support of existing experiences and the inception of new forms of SI. The experience is rich in contrasts regarding the role played by public policies for SI.

We now analyze how a set of public policies in Argentina and Brazil acted to create, support, and also insert movements of SI in the areas of family farming (Pro-Huerta program), water supply (P1MC), and technologies for social inclusion (PNTIS).

\section{Pro-Huerta program}

Pro-Huerta is a large-scale rural and semiurban farming program designed by the National Institute of Agricultural Technology (INTA), a mainstream research and development institution in Argentina. The program started as a clear top-down initiative in a context of severe economic and social depression and growing unemployment in the early 1990s. In 2003, only a year after the deep economic, social, and political crisis, Pro-Huerta was included in the Food Security National Program, supported by the Ministry of Social Development. The original goal of the program was to foster food self-production, food security, and capacity building among the poorest populations.

Pro-Huerta provides small tools for farming along with seeds, small farm animals, and gardening manuals. According to INTA, the program covers more than 3.4 million people in approximately 600,000 productive units, including family farms, community farms, public schools, and cooperatives, covering most of the Argentinean territory (INTA 2011).

The program combines the supply of materials and tools with training courses, which allow beneficiaries to start building a small farm. In this sense, Pro-Huerta is a top-down direct intervention government action.

The initial design of tools and inputs was decided by INTA with scarce participation from users. As a result, the program faced some difficulties at the beginning. For example, because of the large diversity of ecological characteristics in Argentina, not every plant selection worked or suited the local diet. However, as the Pro-Huerta advanced, technicians started to include new strategies and plant selections, and especially new participatory schemes that allowed users and technicians to share and coproduce knowledge and, in this sense, generate new technological solutions.

Nowadays, Pro-Huerta relies on social promoters and active user participation for the implementation of the program. It also combines research on agroecology and small-farm tools with local social work with promoters of the Ministry of Social Development and the INTA. Perhaps one of the most interesting characteristics of Pro-Huerta is the fact that the actions of the program triggered a series of actions, such as the organization of local producer fairs, seed fairs, and knowledge-exchange schemes in family farming production as spaces for the development of a social economy. These social organization aspects can be regarded as SIs promoted by a national policy and national institutions, in close collaboration with local actors, local governments, and NGOs.

However, the Pro-Huerta program's scope needs to be put into perspective relative to the broader picture of agricultural policy in Argentina. Although Pro-Huerta has been successful in creating an extensive new practice of family farming that 
empowers the poorest population and makes it possible to experiment with schemes of solidarity economy, it has several difficulties to transcend this level and challenge, for example, massive transgenic agribusiness based on soybean production.

\section{The One Million Cisterns Program}

P1MC, or Cisterna ("cistern water tank" in English), as it became widely known, was aimed at building a massive number of water cisterns in a large semiarid region in northeastern Brazil, with a population of approximately 25 million people. This region is characterized by low levels of rainfall and scarce groundwater sources. Water scarcity and poverty were usually attended by an instrumental government approach that favored huge infrastructure projects for massive agriculture, combined with aid solutions, such as water tankers (carro-pipa) and the provision of food aid for the poor. These aid schemes ultimately reinforced local political patronage and increased inequalities (Alves da Silva 2003).

The P1MC program was originally devised by the Semi-Arid Association (ASA) as an answer for paternalistic schemes of aid in the region, known as the "industry of drought" (indústria da seca). ASA is a network of more than 700 institutions, social movements, NGOs, and farmer groups. ASA was originated in the popular mobilization spurred by the industry of drought and later became an important actor of the Social Technology Network (RTS). Instead of relying on water supplied by water tanker provided by local politicians, ASA proposed to build simple cement-layered containers that collect rainwater from the roof, with a capacity of about $16,000 \mathrm{~L}$, enough to sustain a family's needs through the region's drought season.

With the arrival of the center-left government of Lula da Silva in 2003, the ASA found the opportunity to insert this program into national development policies, to be funded by the Ministry of Social Development. Later, in 2005, the Cisterna program also became part of the reapplied technologies of the RTS. Since its launch in 2003, more than 549,000 water cisterns have been built and put in place by local inhabitants with the support of the RTS and the Ministry of Social Development.

The main feature of the technology is that it is built by its "users," i.e., farmers/masons, a common archetype of the Brazilian semiarid region. The self-building aspect of the cistern was oriented to foster relation building in the community, through the process of learning how to build, use, and modify the technology, indicating a strong link with empowering and participatory framing practices. The water system empowers local people in the building process, while also providing autonomy from local governments and private water suppliers.

P1MC was one of the most successful cases of RTS intervention in terms of scale. Moreover, it was paradigmatic in that a public program was able to embody most of the social technology framing in terms of participation and negotiations of knowledge between local inhabitants and technicians. This model of horizontal participation used for the construction of the cistern was explicitly positioned as an alternative to aid schemes and big infrastructure programs, both of which excluded the users from the decision-making process. Participation empowered people and strengthened the link with the mobilization of the ASA in the search for alternative ways of development.
However, the insertion of this model into a government program became problematic in early 2012, when the Brazilian government announced a plan to speed up the implementation of the program through the purchase of 300,000 plastic water cisterns, at almost twice the price of the original scheme. Focused on outcomes, this policy change disregarded the process of participation and empowerment that was central to the design of the program. In addition, some private companies saw a business opportunity in the proposal (see R. Dias, unpublished manuscript).

The narrowing of the scope of the model by the national government led 15,000 farmers to rally on 20 December 2011, in the city of Petrolina (Pernambuco), marching against the plastic cistern initiative (Passos 2011). Protestors claimed that changes in management disempowered people from participation in the construction. Another element of the controversy included concern that introduction of plastic cisterns would enable local political elites to regain power over water distribution, by controlling the market of plastic water cisterns.

For almost a decade, this model was very successful in building more than 500,000 cisterns and empowering the population of the semiarid region. The P1MC was also transformed into a national public policy through the Water for Everyone program, of the Ministry of Social Development (Costa and Dias 2013). This case shows that SI and social technologies can be created and mobilized by grassroots action and then inserted into national public policies, in a bottom-up process. However, this insertion is not unproblematic, and tensions between different aims and practices remain.

A careful discussion of SI is needed to shelter these experiences from incumbent practices at the government level. However, this example also shows the limitations of the strategy of direct intervention and linkage making, because, even with the support of national ministries and other institutions, this program, along with the umbrella network of RTS, struggled to further expand its own way of working and have real influence in mainstream policies of science and technology.

The National Technology and Social Innovation Program at the Ministry of Science, Technology and Innovation ${ }^{[3]}$

The Argentinean Ministry of Science, Technology and Innovation (MINCYT) created PNTIS in 2012 to foster the creation, use, and diffusion of knowledge for social development. PNTIS grouped MINCYT's existing instruments aimed at SI. Among them, PROCODAS is a funding program for technology for social inclusion projects. The program funds small-scale projects that create solutions to a social or productive demand. PNTIS adopts a demand-pull model instead of a science-push approach. PROCODAS's focus is on fostering linkages between social demands and universities and public research organizations for the cocreation of small-scale technological solutions. PROCODAS was relaunched in 2012, and priority areas were adopted for better targeting, including (1) social economy, (2) family farming, (3) habitat, and (4) technology for the inclusion of persons with disabilities. Another innovation adopted in the program's governance implied broadening the profile of experts in the evaluation commission. In addition to academic specialists from each field, public officials from sectorial programs were invited, as well as social practitioners. This allowed for an evaluation process with wider criteria, focused not only on the 
Table 1. Case-study summary and typology.

\begin{tabular}{lll}
\hline \hline Case & Typology of Public Policy for SI & SI Outcomes \\
\hline Pro-Huerta (Argentina) & Direct intervention & $\begin{array}{l}\text { Knowledge creation, } \\
\text { productive capacities, } \\
\text { social movement identity, and mobilization } \\
\text { capacities }\end{array}$ \\
P1MC (Brazil) & Direct intervention and linkage making & $\begin{array}{l}\text { Productive capacities, but PP reduced } \\
\text { knowledge creation and social movement } \\
\text { identity and mobilization capacities } \\
\text { Linkages between research system and social } \\
\text { movements, limited establishment of an } \\
\text { aldernative research agenda }\end{array}$ \\
\hline
\end{tabular}

P1MC, One Million Cisterns Program; PNTIS/MINCYT, National Technology and Social Innovation Program/Ministry of Science, Technology and Innovation; PP, public policy; SI, social innovation.

Source: Own elaboration.

academic excellence of proposals, but also on social relevance, potential impact, and potential for coordination with sectoral public policies, for instance, coordination with health and education policies for the inclusion of people with disabilities.

Acknowledging the program's weakness in terms of limited funding, the decision to incorporate other governmental organizations in the evaluation commission aimed at improving coordination and fostering linkages to attract additional public partners for the funded projects. On the one hand, this enabled a virtuous cycle of crowding in other public funding. On the other hand, having other public organizations "onboard," technology for social inclusion projects gave these organizations valuable insights for their own public policy design and assessment processes. After 4 years, the result of this engagement process with other public organizations has been mixed. There have been advancements in certain areas, mostly where previous informal ties between public officials existed, whereas there has been little in others. One hypothesis is that the innovative nature of the public policies involved in SI initiatives, where social actors have a leading role in the design of solutions, goes against established routines and requires the existence of confidence from officials for implementation. The importance of informal networks in the establishment of linkages between public and private organizations with different cultures and goals is therefore stressed.

The PNTIS falls into the category of linkage-making public policy. It does not provide social goods, nor does it directly implement solutions. It is a promotion and coordination program that has two funding instruments for projects. The design of the call for proposals is intended to foster coordination with social actors within the science and technology system. Project proposals have to be cocreated between beneficiaries and science and technology partners. The short-term objective of the program is to provide a technological solution to a social demand, whereas the longer-term goal is to foster an agenda within the science and technology community on user-inspired research that addresses social needs (Table 1).

\section{CONCLUSIONS AND DISCUSSION}

We sought to advance the understanding of the relation between SI and public policies. Understood as a boundary concept, SI is subject to interpretation and power games from different actors (Pel and Bauler 2014), thus expressing a dialectic relation with public policies and institutionalization as a whole. Moreover, as Haxeltine et al. (2016:21) point out, the concept of TSI expresses "rather than a type of innovation ... a process that alters existing patterns of structuration resulting in varying degrees of institutionalization as a TSI journey unfolds across time and space."

Based on examples from Argentina and Brazil, we intended to show how SI has risen as an answer to certain problems caused by economic crisis and long-term inequalities. By doing so, SI initiatives attempted to experiment with different pathways of transformation and social inclusion. Instead of replacing public policies, these were fundamental to the process of scaling-up and widening the scope of SI, while at the same time transforming SI initiatives in a dialectic relation.

As we have observed in the analysis of these cases, the economic and financial crises of the early 2000s triggered a wave of SI in Argentina and Brazil. At the same time, SI and grassroots activities were creating new models of innovation and social inclusion along with social movements that were supported by the Workers' Party in Brazil. This scenario seems to fit the hypothesis of SI arising as a creative answer to intractable problems and new challenges. However, beyond this point, the picture of SI and its relation with public policy in Argentina and Brazil is quite different.

A first important point in this difference is that public policies played and continue to play a big role in the inception, support, and sheltering of SI in Argentina and Brazil. The new public policy capabilities created in a context of populist governments were central in the support of social movements and SI. However, more importantly for our argument, public policies were also important as initiators of new programs and experiences that led to increasing experimentation in SI. 
The second point we want to highlight is how public policies helped the creation and sheltering of alternative forms of agriculture, social economy, and cognitive practice. Public policies oriented toward SI can be fundamental to providing a sheltered space for the experimentation and development of these experiences. Furthermore, as the case of Pro-Huerta shows, after 20 years of continuous support this can also lead to the consolidation of an alternative regime of organic agriculture. ProHuerta and the experience of the Brazilian semiarid region are also important to show how public support can foster SI within the networks, but also beyond them, creating spaces for other social groups to build up alternatives like organic markets and seed markets in the Pro-Huerta case and creating links with other technologies like organic agriculture in the case of the semiarid region. Schemes like funding and technical support provided by PNTIS and other programs can become helpful tools for nurturing and sheltering SI, by fostering linkages between social actors and the science and technology community. Other programs, like public procurement of local agroecological food in Brazil, are also providing continuity and foreseeability to these experiences. All these tools and programs can be devised and implemented by public policy as modes of linkage and direct intervention, to induce and shelter SI.

All these activities and active public support were possible because public policies gained centrality, but also because they created spaces to experiment with hybrid forms of linkages with civil society organizations, social movements, cooperatives, and NGOs. Not only that; rather than a reduction of government capabilities, there was an effort to strengthen public institutions and expand government spheres of intervention.

Nevertheless, as we have seen in the previous cases, even with an active government, SI experiences that are quite extended programs with national reach can struggle to go beyond the initial boundaries set by the public policy and turn into effective local game changers. SI involves processes of empowerment and disempowerment as two sides of the same coin (Haxeltine et al. 2016). This is where we think that the relation between public policies and SI experiences has to be reconfigured. This relation needs new mechanisms to scale up feedback, so that the expansion of SI initiatives reflects the expansion of public policy, and vice versa. It is not enough for a robust government to foster SI experiences: the social movement needs an inner momentum to achieve its transformative role. Also, SI public policy needs its own inner legitimization mechanism. These features are the core set of the relation between government and social innovation.

${ }^{[1]}$ The theoretical antecedents of this approach go back to the seminal works of Marx and Schumpeter. However, for a more recent discussion, please refer to STEPS Centre (2010) and Becerra and Thomas (2017).

${ }^{[2]}$ Lula da Silva assumed the Brazilian Presidency on 1 January 2003, as the first president from the Partido dos Trabalhadores (Workers' Party), after competing in four elections. Néstor Kirchner, in turn, assumed the Argentinean presidency on 25 May 2003 as part of a center-left coalition among the hegemonic Partido Justicialista (Peronist Party).

${ }^{[3]}$ In Spanish, these are the Programa Nacional de Tecnología e Innovación Social and the Ministerio de Ciencia, Tecnología e Innovación Productiva, respectively.
Responses to this article can be read online at: http://www.ecologyandsociety.org/issues/responses. php/9493

\section{Acknowledgments:}

A previous version of this paper was presented at the TRANSIT project synthesis workshop on game changers and transformative social innovation, held on 1-2 September 2014 in Rotterdam. TRANSIT is an international research project cofunded by the European Commission that aims at developing a theory of transformative social innovation useful to both research and practice. The TRANSIT consortium consists of 12 partners across Europe and Latin America. Many of the ideas discussed in this paper owe to the insightful comments and thoughtful feedback received from colleagues from the TRANSIT project; however, the paper's contents are solely the responsibility of the authors.

\section{LITERATURE CITED}

Alves da Silva, R. M. 2003. Entre dois paradigmas: Combate à seca e a convivência com o semi-árido. Sociedade e Estado 18 (1/2):361-385. http://dx.doi.org/10.1590/S0102-69922003000100017

Avelino, F., J. Wittmayer, A. Haxeltine, R. Kemp, T. O'Riordan, P. Weaver, D. Loorbach, and J. Rotmans. 2014. Game changers and transformative social innovation: the case of the economic crisis and the new economy. Transformative Social Innovation Theory (TRANSIT) Working Paper 1. TRANSIT, Rotterdam, the Netherlands. [online] URL: http://www.transitsocialinnovation. eu/content/original/Book $\% 20$ covers/Local $\% 20$ PDFs $/ 178 \%$ 20TRANSIT WorkingPaper1 Gamechangers Avelino.pdf

Becerra, L., and H. Thomas. 2017. Innovation, cooperatives and inclusive development: rethinking technological change and social inclusion. Pages 99-116 in P. North and M. S. Cato, editors. Towards just and sustainable economies: the social and solidarity economy North and South. Policy, Bristol, UK.

Bekkers, V. J. J. M., L. G. Tummers, B. G. Stuijfzand, and W. Voorberg. 2013. Social innovation in the public sector: an integrative framework. LIPSE Working Paper Series No. 1. Erasmus University Rotterdam, Rotterdam, the Netherlands.

Bureau of European Policy Advisors (BEPA), European Commission. 2011. Empowering people, driving change. Social innovation in the European Union. Publications Office of the European Union, Luxembourg.

Costa, A. B., and R. Dias. 2013. Políticas públicas e tecnologia social. Algunas liçoes das expêriencias em desenvolvimento no Brasil. Pages 223-246 in A. Costa, editor. Tecnologia Social e Políticas Públicas. Fundação Banco do Brasil, São Paulo, Brazil.

Franz, H.-W., J. Hochgerner, and J. Howaldt. 2012. Challenge social innovation: potentials for business, social entrepreneurship, welfare and civil society. Springer, Berlin, Germany. http://dx.doi. org/10.1007/978-3-642-32879-4

Fressoli, M., E. Arond, D. Abrol, A. Smith, A. Ely, and R. Dias. 2014. When grassroots innovation movements encounter mainstream institutions: implications for models of inclusive 
innovation. Innovation and Development 4(2):277-292. http://dx. doi.org/10.1080/2157930X.2014.921354

Haxeltine, A., F. Avelino, B. Pel, A. Dumitru, R. Kemp, N. Longhurst, J. Chilvers, and J. M. Wittmayer. 2016. A framework for transformative social innovation. Transformative Social Innovation Theory (TRANSIT) Working Paper 5. TRANSIT, Rotterdam, the Netherlands. [online] URL: http://www. transitsocialinnovation.eu/content/original/Book $\% 20$ covers/Local $\%$ 20PDFs $/ 240 \% 20$ TRANSIT WorkingPaper no5 TSI $\%$ 20framework Haxeltine $\% 20$ et $\% 20$ al November2016 AH041116. pdf

Haxeltine, A., A. Flor, J. Wittmayer, R. Kemp, P. Weaver, J. Backhaus, and T. O'Riordan. 2013. Transformative social innovations: a sustainability transition perspective on social innovation. Pages 1-19 in International Conference Social Frontiers: the next edge of social innovation research (London, 14-15 November 2013). Nesta, London, UK. [online] URL: http://kemp.unu-merit.nl/pdf/Haxeltine $\% 20$ et $\% 20$ al. $\% 202013 \% 20$ TSI $\%$ 20Transition $\% 20$ Perspective.pdf

Instituto Nacional de Tecnología Agropecuaria (INTA). 2011. Plan operativo anual 2011. INTA, Buenos Aires, Argentina. [online] URL: http://inta.gob.ar/sites/default/files/script-tmppoa 2011.pdf

Latour, B. 2005. Reassembling the social: an introduction to actornetwork theory. Oxford University Press, Oxford, UK.

Mulgan, G. 2006. The process of social innovation. Innovations 1(2):145-162. http://dx.doi.org/10.1162/itgg.2006.1.2.145

Passos, N. 2011. Na 'guerra das cisternas', 15 mil protestam no sertão contra governo. Carta Maior, 20 December. [online] URL: http://www.cartamaior.com.br/?/Editoria/Movimentos-Sociais/Naguerra-das-cisternas-15-mil-protestam-no-sertao-contra-governo/2/18388

Pel, B., and T. Bauler. 2014. The institutionalization of social innovation: between transformation and capture. Transformative Social Innovation Theory (TRANSIT) Working Paper 2. TRANSIT, Rotterdam, the Netherlands. [online] URL: http:// www.transitsocialinnovation.eu/content/original/Book $\% 20$ covers/ Local $\% 20$ PDFs $/ 179 \% 20$ TRANSIT WorkingPaper2 Governance Pel141015.pdf

Rip, A., and B. J. R. van der Meulen. 1996. The post-modern research system. Science and Public Policy 23(6):343-352. https:// doi.org/10.1093/spp/23.6.343

Seyfang, G., and A. Haxeltine. 2012. Growing grassroots innovations: exploring the role of community-based initiatives in governing sustainable energy transitions. Environment and Planning C: Government and Policy 30:381-400. http://dx.doi. org/10.1068/c10222

Smith, A., and R. Raven. 2012. What is protective space? Reconsidering niches in transitions to sustainability. Research Policy 41(6):1025-1036. http://dx.doi.org/10.1016/j.respol.2011.12.012

STEPS Centre. 2010. Innovation, sustainability, development: a new manifesto. STEPS Centre, Brighton, UK. 